\title{
CINegeo
}

International Journal of Environment and Geoinformatics (IJEGEO) is an international, multidisciplinary, peer reviewed, open access journal.

\section{Evaluating the Geometric Accuracy of Large Scale Digital Orthophotos Produced from Aerial Photography}

\section{Ozan ARSLAN, Pinar YILMAZ}

\author{
Chief in Editor \\ Prof. Dr. Cem Gazioğlu \\ Co-Editors \\ Prof. Dr. Dursun Zafer Şeker, Prof. Dr. Şinasi Kaya, \\ Prof. Dr. Ayşegül Tanık and Assist. Prof. Dr. Volkan Demir
}

Editorial Committee (December 2020)

\begin{abstract}
Assos. Prof. Dr. Abdullah Aksu (TR), Assit. Prof. Dr. Uğur Algancı (TR), Prof. Dr. Bedri Alpar (TR), Prof. Dr. Levent Bat (TR), Prof. Dr. Paul Bates (UK), İrşad Bayırhan (TR), Prof. Dr. Bülent Bayram (TR), Prof. Dr. Luis M. Botana (ES), Prof. Dr. Nuray Çağlar (TR), Prof. Dr. Sukanta Dash (IN), Dr. Soofia T. Elias (UK), Prof. Dr. A. Evren Erginal (TR), Assoc. Prof. Dr. Cüneyt Erenoğlu (TR), Dr. Dieter Fritsch (DE), Prof. Dr. Çiğdem Göksel (TR), Prof.Dr. Lena Halounova (CZ), Prof. Dr. Manik Kalubarme (IN), Dr. Hakan Kaya (TR), Assist. Prof. Dr. Serkan Kükrer (TR), Assoc. Prof. Dr. Maged Marghany (MY), Prof. Dr. Michael Meadows (ZA), Prof. Dr. Nebiye Musaoğlu (TR), Prof. Dr. Masafumi Nakagawa (JP), Prof. Dr. Hasan Özdemir (TR), Prof. Dr. Chryssy Potsiou (GR), Prof. Dr. Erol Sarı (TR), Prof. Dr. Maria Paradiso (IT), Prof. Dr. Petros Patias (GR), Prof. Dr. Elif Sertel (TR), Prof. Dr. Nüket Sivri (TR), Prof. Dr. Füsun Balık Şanlı (TR), Prof. Dr. Uğur Şanlı (TR), Duygu Ülker (TR), Prof. Dr. Seyfettin Taş (TR), Assoc. Prof. Dr. Ömer Suat Taşkın (US), Assist. Prof. Dr. Tuba Ünsal (US), Dr. İnese Varna (LV), Dr. Petra Visser (NL), Prof. Dr. Selma Ünlü (TR), Prof. Dr. Murat Yakar (TR), Assit. Prof. Dr. Sibel Zeki (TR)
\end{abstract}

Abstracting and Indexing: TR DIZIN, DOAJ, Index Copernicus, OAJI, Scientific Indexing Services, International Scientific Indexing, Journal Factor, Google Scholar, Ulrich's Periodicals Directory, WorldCat, DRJI, ResearchBib, SOBIAD 


\title{
Reaserch Article
}

\section{Evaluating the Geometric Accuracy of Large Scale Digital Orthophotos Produced from Aerial Photography}

\author{
Ozan Arslan ${ }^{1,}$ * iD, Pınar Yılmaz ${ }^{2}$ iD \\ ${ }^{1}$ Geomatics Engineering Dept., Engineering Faculty, Kocaeli University, 41001 Kocaeli, Turkey \\ ${ }^{2}$ Geomatics Engineering Dept, Institute of Science, Kocaeli University, 41001 Kocaeli, Turkey \\ * Corresponding author: Ozan Arslan \\ E-mail: oarslan@kocaeli.edu.tr
}

Received 29 Apr 2020

Accepted 14 Sep 2020

How to cite: Arslan O. and Yilmaz P. (2020). Evaluating the Geometric Accuracy of Large Scale Digital Orthophotos Produced from Aerial Photography International Journal of Environment and Geoinformatics (IJEGEO), 7(3):265-271. DOI:10.30897/ijegeo.729587

\begin{abstract}
This paper aims to assess the geometric accuracy of large-scale digital orthophoto produced from aerial photography in the project area. Since accuracy assessment of digital orthophotos is a complicated issue some main factors and parameters that affect digital orthophoto accuracy are briefly explained and discussed throughout the study. For this aim it is investigated the accuracy of digital orthophotos produced in a project for large scale (i.e. 1/1000) digital photogrammetric map and orthophoto production in Kocaeli city. The estimated orthophoto accuracies in the project were found to be quite adequate and acceptable according to the national and international standards. The results also serve for a crucial approach for the usability and cost efficiency of digital orthophoto imagery for the production of large scale national standard maps. ses
\end{abstract}

Keywords: Orthophoto, Accuracy, DEM, Aerial Triangulation, Accuracy Assessment, Photogrammetric Triangulation

\section{Introduction}

Digital orthophotos are popular digital products due to the increasing need for digital spatial information, diversity of usage, its direct integration into geographic databases and being more sensitive and more useful than traditional data sources. The importance of digital orthophoto has increased significantly thanks to the wide possibilities in sophisticated mapping tools and systems. Produced faster and less costly with the developing technology, orthophotos are one of the mostly used photogrammetric products for high planimetric accuracy of image details. Through the historical development process, digital orthophoto production methods have improved in terms of cost and accuracy. It is known that there are many factors affecting digital orthophoto accuracy; i.e. accuracy of orientation parameters, ground control point accuracy, digital terrain model (DTM) accuracy used in orthorectification and image matching accuracy. On the other hand, determining the orientation parameters with the measurements performed during the flight with the GPS / IMU system has been one of the fundamental issues in the development of photogrammetric triangulation and direct georeferencing methods (Bahadur and Nohutçu, 2020). Since there is a linear relationship between the positional accuracy and the accuracy of the orientation elements; studies have been carried out on GPS / IMU error sources, photogrammetric triangulation accuracy, horizontal control point requirement, direct orientation accuracy and error sources.
Digital orthophoto production is a complex process that consists of many stages and includes sources of error that can propagate to orthophotos in each step. For this reason, the accuracy assessment of the produced digital orthophotos is a complicated subject. Much work has been carried out on the accuracy of digital orthophotos. It is known that orthophoto accuracy is dependent on several parameters, i.e. final accuracy is variable based on the choice of values on various parameters. Some researchers have explored the positional quality of digital orthophotos obtained by unmanned aerial vehicles (UAV). The UAV orthophotos were assessed with various spatial quality tests used by international mapping services. Results showed that the orthophotos satisfactorily provided the spatial quality standards. (Çelik and Gazioğlu, 2020; Sai et al., 2019; Karasaka, et al., 2017; Bayram et al., 2015; Mesas-Carrascosa, et al., 2014; Dalamagkidis, et al., 2008; Chiabrando, et al., 2011; Grenzdörffer, et al., 2008).

There are also some studies dealing with conventional orthoimage problems caused by aerial images of urban areas, especially relief displacements caused by manmade objects, occlusions and loss of information. An approach has presented to produce more accurate orthoimages based on elevation models. The approach used the digital building model in addition to DTM in the orthorectification process. (Amhar and Ecker, 1995; Rau, et al., 2002; Ettarid, et al., 2005)

Some studies have suggested automatic generation of a distortion-free ortho-image, where surfaces of buildings 
(and other objects) were extracted automatically in order to rectify the images. It is declared that even where buildings are correctly included in the DSM, occluded areas might cause parts of the occluding objects to be duplicated on the ortho-image (Fradkin and Ethrog, 1997; Smith, et al., 1997).

There are some researches for orthophotos generated by using a non-metric camera mounted on a drone and digital images obtained from different flying heights. For accuracy assessment root mean square error (RMSE) values were calculated by comparing the digital elevation model (DEM) and orthophoto. As a result, it was observed that accuracy values changed insignificantly and all of these values were sub-meter level. It is possible to use low-cost devices for large scale orthophoto production. (Udin and Ahmad, 2014).

The effect of radiometric conditions on images captured in various lighting and weather conditions for the orthophoto production was also examined. It has shown that poor weather conditions affect radiometric resolution negatively and so orthophoto accuracy decreases (Wierzbicki, et al., 2015).

Pixel size effect was also investigated for orthophoto accuracy. Three different DEMs were produced with ground sample distances (GSD) of $10 \mathrm{~cm}, 30 \mathrm{~cm}$, and 50 $\mathrm{cm}$ to analyze the geometric accuracy. Although the highest geometric accuracy was obtained with the smallest pixel size all accuracy values provided international standards (Kulur, et al., 2016).

In this study, it is aimed to investigate the accuracy of digital orthophotos produced in a project called " 1/1000 large scale digital photogrammetric map and color orthophoto production in Kocaeli " (Arslan, 2010).

\section{Materials and Methods}

In the digital orthophoto production process, aerial triangulation is implemented by using near-vertical aerial photographs in order to determine the exterior orientation parameters and calculate the 3-dimensional coordinates of unknown points. The information of the interior orientation parameters is obtained from the camera calibration file. For the purpose of eliminating displacements due to terrain relief and perspective of images, the rectification process is applied. DEM produced from stereo models is used for orthorectification. As a consequence of this process, a perspective image is turned into orthogonal projection (Simard 1997), and orthophoto is generated as a final product. For the representation of larger areas, the generated orthophotos are merged and named as mosaic. In the course of producing mosaic, although orthophotos are geometrically corrected, radiometric problems such as tone differences are encountered. These problems are eliminated by using appropriate methods (Ioannou and Georgopoulos, 2013). The digital orthophoto production process is shown in Figure 1.

The need for reliable data for many rising applications has led to the development in orthophoto production and hence finding ways to make it better in terms of its geometric accuracy. This paper looks at the creation of an orthophoto and enumerates the factors that ensure the geometric accuracy of the orthophoto. Users of orthophotos need to know the quality of the underlying parameters since this affects the geometric accuracy of the orthophoto. As is known the following parameters directly affect the geometric accuracy of the digital orthophoto (Krupnik, 2003):

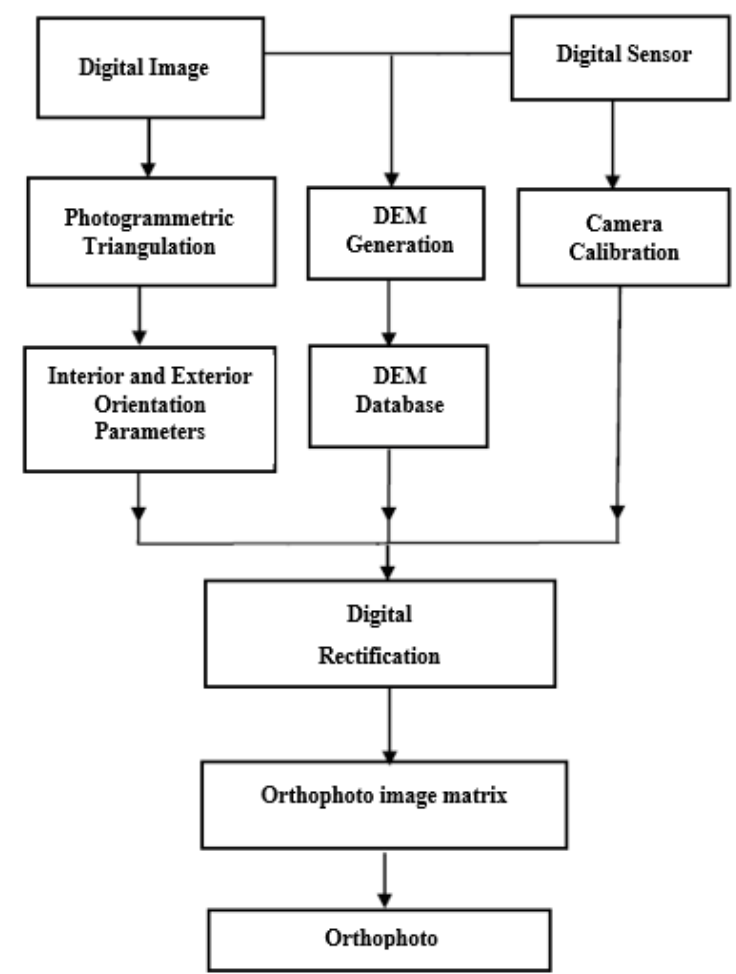

Figure 1. Digital orthophoto generation procedure

- Transformation parameters between image and photo coordinate systems

- Exterior orientation parameters

- Ground control points

- $\quad$ Elevation values obtained from DEM

In general, the parameters to which the geometric accuracy of an orthophoto are dependent are shown in Figure 2.

\section{Study Area}

The city of Kocaeli is mainly an industrial center in Marmara region of Turkey with numerous industrial establishments surrounding the Gulf of Izmit. The 1999 Kocaeli earthquake that shook Marmara Region caused immense loss of life and property and damaged the social and economic life of our country.

The geomorphological and geotechnical features of the İzmit Bay entail a special interest for vertical kinematics of the basin at least for the horizontal regime of the North Anatolian Fault System (NAFS). The basin deposits and its ground conditions had endangered a devastating effect increasing the damage of the Izmit 
earthquake. In progress of time, fault motions induce positional deformation at the ground control points (GCPs). In the orthophoto production process, ground control points are used for determining the exterior orientation parameters with the help of collinearity equations. Also, when determining the accuracy of orthophoto, the actual coordinate values of the GCPs and the measured values from orthophoto are compared. Therefore, deformations at these points directly affect orthophoto accuracy.

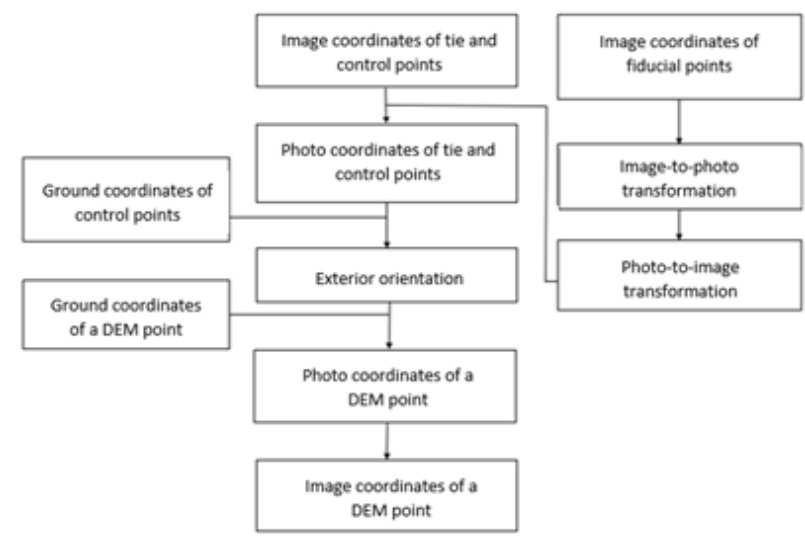

Figure 2. Schematic diagram of the parameters affecting accuracy in digital orthophoto production process (Krupnik, 2003)

\section{Flight Plan}

A detailed flight planning is a basic prerequisite for a successful acquisition of airborne datasets. Given the definition of the products to be obtained from a flight mission and their technical requirements, the mission planning accounts for multiple steps that could be briefed as follows: Selection of a suitable sensor (camera) and platform, flight plan design, and analysis of the factors to be controlled during flight operations. Prior to the preparation of the flight plan, current GCPs were checked to determine whether or not the study area is suitable for flight. After all these controls, flight plan was prepared in WGS84 datum system and in $6^{\circ} \mathrm{UTM}$ coordinate system. Study area consisted of 67 blocks which has a rectangle form in accordance with the flight plan. GSD was chosen as $8 \mathrm{~cm}$. By having the use of onthe-board GPS/IMU devices, we were able to determine the coordinates of the perspective center and the rotations of 3 axes. Perspective center coordinates were obtained by using the sufficient numbers of GPS satellites, and the standard deviation was varied between $2 \mathrm{~cm}$ and $4 \mathrm{~cm}$. Table 1 summarizes the other technical information about the flight plan.

\section{Image Acquisition}

For this study, digital images were captured by the large format digital aerial camera system, i.e. Vexcel UltraCam X camera. The sensor serves as the versatile airborne sensor for application in many different project scenarios. The short frame interval enables the sensor to acquire images at large scale and at rather high stereoscopic overlaps. The radiometric bandwidth and the multispectral capability of the camera offer a dynamic range of more than 12 bit per band and simultaneous infrared acquisition. The geometric accuracy of the sensor makes possible to achieve noteworthy results from aerotriangulation and bundle adjustment.

Table 1. Summary of the flight plan parameters

\begin{tabular}{|l|r|}
\hline Perpendicular image side in ground units $(\mathrm{m})$ & 1154.4 \\
\hline Parallel image side in ground units (m) & 753.6 \\
\hline Pixel size (micron) & 7.2 \\
\hline Focal length (mm) & 100.5 \\
\hline Ground sample distance (GSD) $(\mathrm{cm})$ & 8 \\
\hline Baselength (m) & 226.08 \\
\hline Image scale & 11111 \\
\hline Distance between strips (m) & 693 \\
\hline Number of the GCP's & 2300 \\
\hline Number of the blocks & 67 \\
\hline Stereomodel area (m $\left.{ }^{2}\right)$ & 1111 \\
\hline Flight altitude (m) & 70 \\
\hline Overlap (\%) & 40 \\
\hline Sidelap (\%) & 869956 \\
\hline Ground area of one photograph (m $\left.{ }^{2}\right)$ & 28569 \\
\hline Number of the models in a strip & 28570 \\
\hline Number of the photographs in a strip & r
\end{tabular}

Some of the specifications of UltraCam X are large image format of 14430 pixels across track and 9420 pixels along track, an optical system with $100 \mathrm{~mm}$ focal length for the panchromatic camera and for the multispectral camera heads, image storage capacity of 4700 frames for one single data storage unit. Multispectral camera specifications are given in Table 2.

Table 2. Technical specifications of the multispectral camera

\begin{tabular}{|l|l|r|r|}
\hline $\begin{array}{l}\text { Image } \\
\text { format }\end{array}$ & $\begin{array}{l}\text { long } \\
\text { track }\end{array}$ & $67.824 \mathrm{~mm}$ & 3140 pixels \\
\hline & $\begin{array}{l}\text { across } \\
\text { track }\end{array}$ & $103.896 \mathrm{~mm}$ & 4810 pixels \\
\hline Image extent & & $\begin{array}{r}(-33.91,-51.95) \\
\mathrm{mm}\end{array}$ & $\begin{array}{r}(33.91,51.95) \\
\mathrm{mm}\end{array}$ \\
\hline Pixel size & & $\begin{array}{r}21.600 \mu \mathrm{m} * \\
21.600 \mu \mathrm{m}\end{array}$ & \\
\hline Focal length & ck & $100.500 \mathrm{~mm}$ & \\
\hline $\begin{array}{l}\text { Principal } \\
\text { point }\end{array}$ & X_ppa & $0.000 \mathrm{~mm}$ & $\pm 0.002 \mathrm{~mm}$ \\
\cline { 2 - 4 } & Y_ppa & $0.144 \mathrm{~mm}$ & $\pm 0.002 \mathrm{~mm}$ \\
\hline $\begin{array}{l}\text { Lens } \\
\text { distortion }\end{array}$ & Remaining distortion less than $0.002 \mathrm{~mm}$ \\
\hline
\end{tabular}

\section{Accuracy of DEM}

As was mentioned in the methods section, generated orthophoto accuracy depends on many parameters such as affine transformation parameters, exterior orientation parameters, the accuracy of GCP, DEM, and terrain slope. Orthorectification of aerial photographs implicate the process of the elimination of geometrical deformations caused by the central projection and vertical distances of terrain using DEM. Since DEM is used to eliminate relief displacement, it is a crucial element of orthophoto production from the point of accuracy. DEM elevation errors propagate through 
collinearity equations. The vertical accuracy of points is obtained by Equation 1 (Simard, 1997).

$$
\frac{\sigma_{h}}{Z}=\frac{\sqrt{2}}{\frac{B}{Z} \cdot f} \cdot \sigma_{p}
$$

where $\sigma \mathrm{h}$ is height error produced, $\sigma \mathrm{p}$ is parallax measure error, $\mathrm{B} / \mathrm{Z}$ is base/height ratio, $\mathrm{f}$ is focal length and $\mathrm{Z}$ is flight height above ground. Utilizing the equation (1), the maximum height error of DEM for this project was $11.1 \mathrm{~cm}$ and the minimum height error was $5.5 \mathrm{~cm}$. Positional accuracy is given by Equation 2 .

$\sigma_{p}=\sqrt{2} \cdot\left(\frac{r}{f}\right) \cdot \sigma_{h}$

where $r$ is the radial distance. Positional error, as shown in Equation 2, is directly proportional to radial distance, and elevation error of the DEM point, while inversely proportional to camera focal length. The positional error Table 3. A priori standard deviations used in the block adjustment

\begin{tabular}{|c|c|}
\hline the ground control points & $\sigma_{\mathrm{X}, \mathrm{Y}}=0.03 \mathrm{~m}, \sigma_{\mathrm{Z}}=0.05 \mathrm{~m}$ \\
\hline the automatic measured tie points & $\sigma=0.002 \mathrm{~mm}$ \\
\hline the image points of ground control and manual measurements & $\sigma=0.002 \mathrm{~mm}$ \\
\hline $\begin{array}{c}\text { the GPS measurements } \\
\text { the INS measurements }\end{array}$ & $\sigma_{\mathrm{X}, \mathrm{Y}, \mathrm{Z}}=0.30 \mathrm{~m}$ \\
$\sigma_{\omega, \phi, \kappa}=0.015(\mathrm{deg})$
\end{tabular}

\section{Assessment of Orthophoto Accuracy}

The empirical accuracy of the study was checked by using some field surveys as check points. In order to evaluate the accuracy of digital orthophoto, RMSE was calculated using the difference values between the photogrammetrically measured points and the knownpoints whose coordinates had been measured in the field. For this, field (survey) measurements of 80 points in Block 5 and 68 points in Block 21 were made. After the coordinate differences were calculated standard value for this project was obtained to be $10.34 \mathrm{~cm}$ in the north-south flight direction when the maximum radial distance was taken as $7.35 \mathrm{~cm}$ along the diagonal.

\section{Results}

During the flight planning stage in the project, 67 photogrammetric blocks were determined and some of them were tested for control purposes. The block is shown in Figure 3. Match-AT software package was used for aerial triangulation implementing bundle adjustment method with additional parameters. The standard deviations of the exterior orientation parameters, the residual values of INS and GPS observations and ground control points and the accuracy of the entire block adjustment were checked. The general assumed a priori standard errors for the photogrammetric aerial triangulation are as following Table 3.

Table 4. Descriptive statistics of positional accuracies obtained from field measurements

\begin{tabular}{|c|c|c|c|c|c|c|}
\hline & \multicolumn{3}{|l|}{ Block 5} & \multicolumn{3}{|l|}{ Block 21} \\
\hline & $\mathrm{dx}(\mathrm{cm})$ & dy $(\mathrm{cm})$ & $\mathrm{dp}(\mathrm{cm})$ & $\mathrm{dx}(\mathrm{cm})$ & dy $(\mathrm{cm})$ & $\mathrm{dp}(\mathrm{cm})$ \\
\hline Mean & 3.23 & 3.68 & 5.56 & 3.19 & 3.75 & 5.34 \\
\hline Stand. Deviation & 2.539 & 2.333 & 2.186 & 2.176 & 1.983 & 2.072 \\
\hline Min & 0 & 0 & 1 & 0 & 0 & 1 \\
\hline $\operatorname{Max}$ & 9 & 8 & 9 & 7 & 7 & 8 \\
\hline Variance & 6.448 & 5.390 & 4.779 & 4.735 & 3.932 & 4.295 \\
\hline RMSE & \multicolumn{3}{|c|}{5.97} & \multicolumn{3}{|c|}{5.79} \\
\hline
\end{tabular}

Then another approach was adopted as a basis for accuracy analysis of the study. Positional and elevation accuracy of digital orthophoto was computed using the deviations were calculated, gross errors were eliminated from the dataset and the process was repeated. The results obtained are summarized in Table 4. Positional accuracy for the project is expected to be below of subpixel level. GSD of this study is determined as $8 \mathrm{~cm}$ level. As can be seen from the table that the obtained positional accuracies were quite similar or slightly different from each other for these blocks. We observe from Table 4 that positional (planimetric) accuracy magnitude is lower than GSD, that is to say, these results confirm the expected accuracy levels. following Block 08, Block 13, Block 19, Block 24, Block 31, Block 37, Block 42, Block 46, Block 49, and Block 63. Figure 3 illustrates these test blocks. 


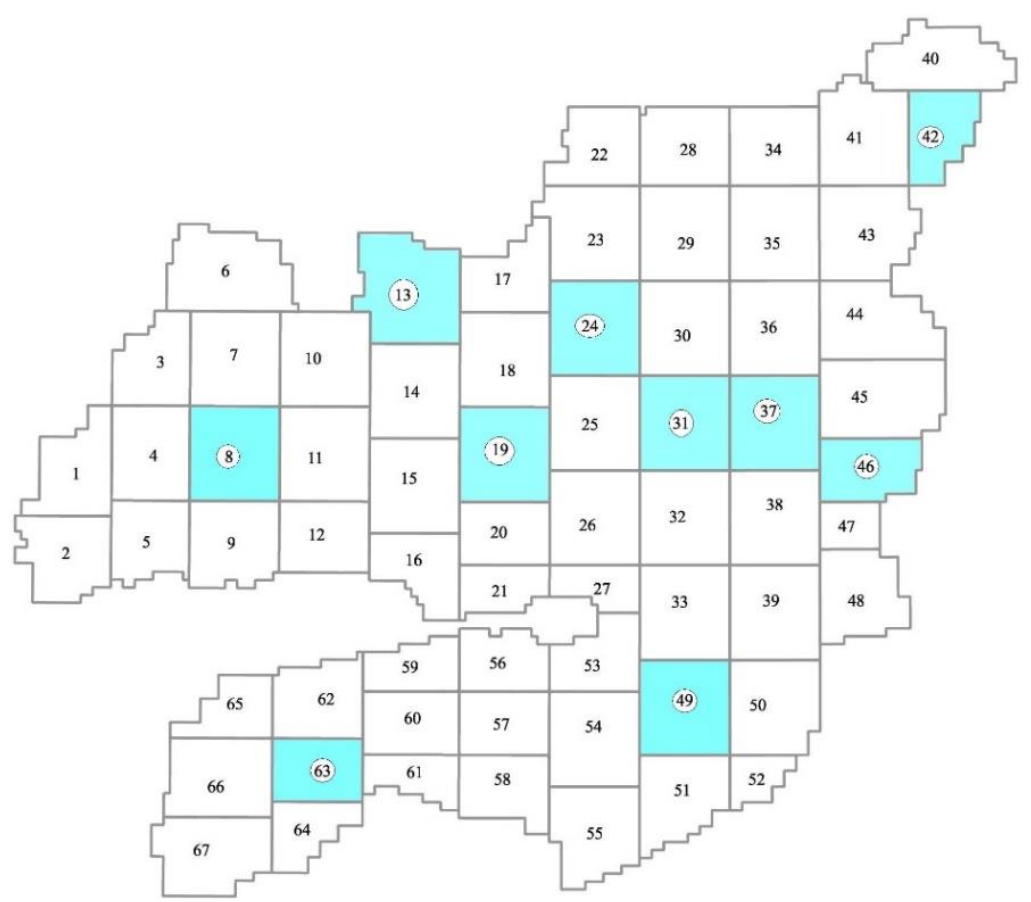

Figure 3. Test blocks used for the accuracy analysis of the produced digital orthophotos

For a general accuracy assessment for computing positional accuracies in the study, stereomodel points were compared to the corresponding (homolog) points in digital orthophotos then descriptive statistics (such as

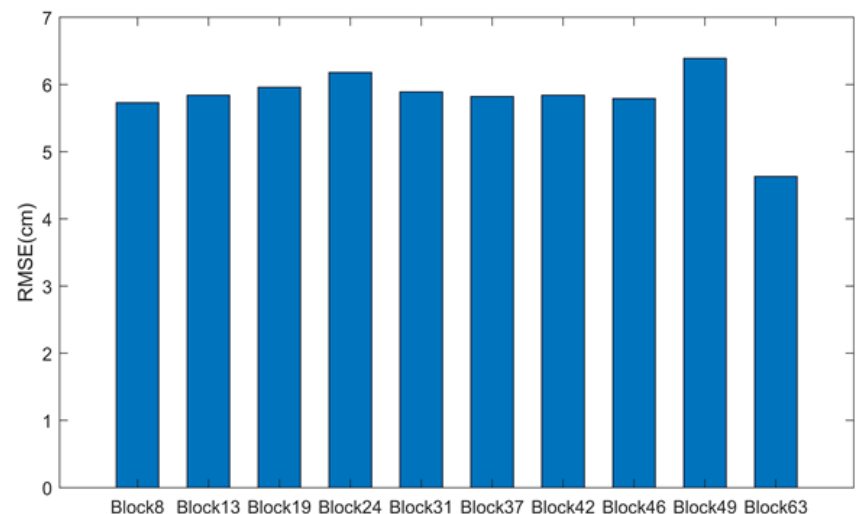

variance, mean error, RMSE) were calculated for this purpose. Positional accuracy for selected blocks is summarized in Figure 4.

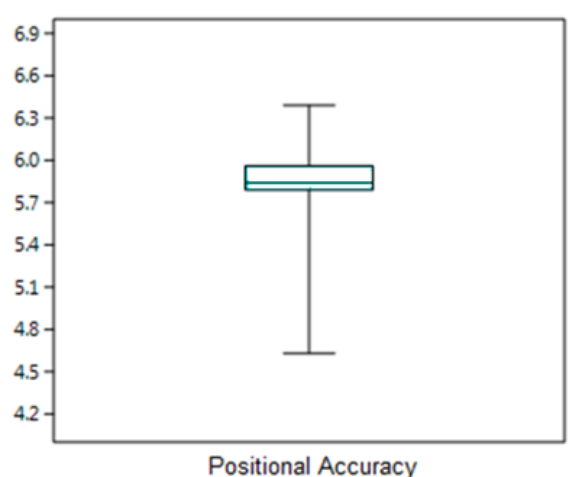

Figure 4. Positional accuracy RMSE values and box plot for the test blocks

It should be noted that the positional accuracy values obtained from all the test blocks were very similar as it shown from the figure. An approximate $6 \mathrm{~cm}$ planimetric accuracy level was observed from these ten test blocks. Boxplot graph was also drawn for visualizing the statistical distribution (i.e. variability) of positional accuracies. We can also use international standards to test whether the resulting values comply with current standards. One of these is the standards established by the American Photogrammetry and Remote Sensing Society (ASPRS). According to the ASPRS Spatial Accuracy Standards published in 2014, horizontal accuracy standard values for the project are given in Table 5. In the instruction the "Accuracy Standards for Digital Geospatial Data, (March 2014)" applied by
ASPRS position and height accuracy of the digital orthophoto images is classified according to method and accuracy values. Class 1 is recommended for high accuracy projects, Class 2 for standard mapping and GIS applications, Class 3 for visualization studies and projects with low accuracy (ASPRS 2015). From the figure 4 , we can see that the maximum horizontal error is $6.39 \mathrm{~cm}$. This value should be less than $8 \mathrm{~cm}$ for high accuracy projects according to ASPRS standards. Hence horizontal accuracy values are within the acceptable limits with regard to the ASPRS standards. In the previous section, we found that the maximum positional error is $10.34 \mathrm{~cm}$ for this study. Therefore, we can say that accuracy values are below the expected limit. 
Table 5. ASPRS Horizontal Accuracy Standards

\begin{tabular}{|c|c|c|c|c|c|}
\hline \multirow[b]{2}{*}{$\begin{array}{l}\text { Orthophoto } \\
\text { pixel size }\end{array}$} & \multirow[b]{2}{*}{$\begin{array}{l}\text { Horizontal } \\
\text { Accuracy Class }\end{array}$} & \multicolumn{3}{|c|}{ Absolute Accuracy } & \multirow{2}{*}{$\begin{array}{l}\text { Orthoimagery } \\
\text { Mosaic Seamline } \\
\text { Mismatch }(\mathrm{cm})\end{array}$} \\
\hline & & $\begin{array}{l}\mathrm{RMSE}_{\mathrm{x}} \text { and } \\
\mathrm{RMSE}_{\mathrm{y}}(\mathrm{cm})\end{array}$ & $\begin{array}{l}\mathrm{RMSE}_{\mathrm{r}} \\
(\mathrm{cm})\end{array}$ & $\begin{array}{l}\text { Horizontal Accuracy at } 95 \% \\
\text { Confidence Level }(\mathrm{cm})\end{array}$ & \\
\hline \multirow{3}{*}{$8 \mathrm{~cm}$} & 1 & 8.0 & 11.3 & 19.6 & 16.0 \\
\hline & 2 & 16.0 & 22.6 & 39.2 & 32.0 \\
\hline & 3 & 24.0 & 33.9 & 58.8 & 48.0 \\
\hline
\end{tabular}

In addition, we used a different scheme for the assessment of elevation accuracy in the study. Elevation accuracy assessment was performed according to two different parameters. One of these parameters is $\mathrm{dz} 1$ which represents the RMSE of differences between the elevation derived from orthophoto and model. The other parameter is dz2 which represents the RMSE of differences between orthophoto and DEM. Figure 5 shows these estimated accuracy values for the test blocks.
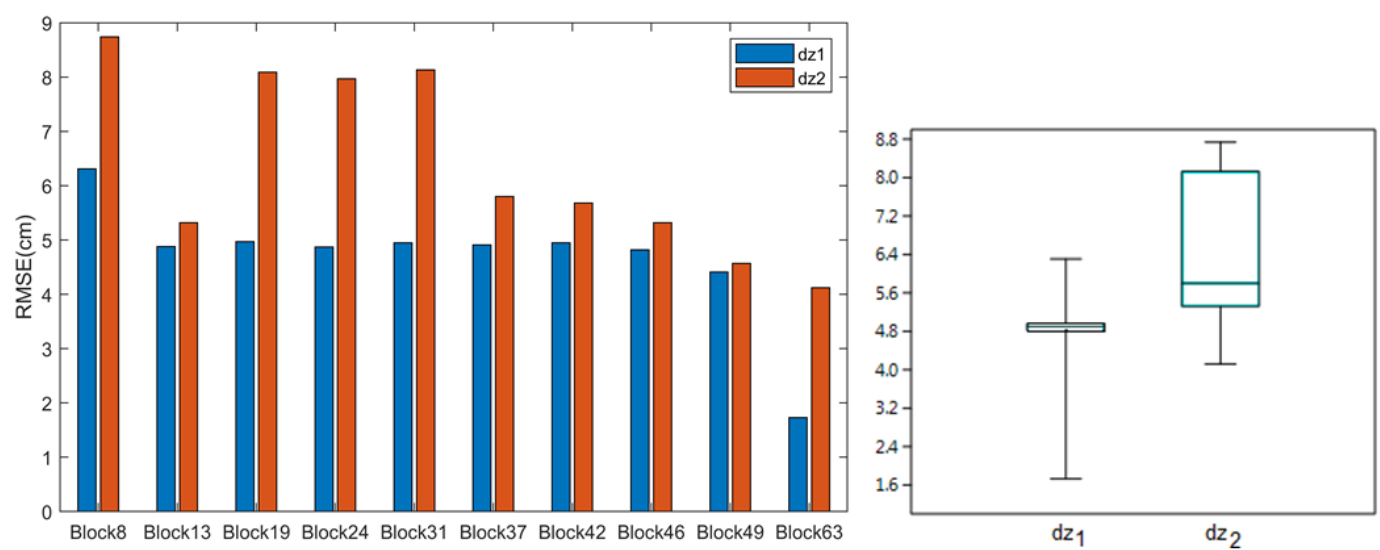

Figure 5. Elevation accuracy RMSE values and box plots for the test blocks

When the accuracy of DEM produced for this project was considered maximum elevation error was estimated as $11 \mathrm{~cm}$. As easily seen from the graph above that estimated elevation errors are within the acceptable limits. Boxplot of the parameters dz1 denoted the normal distribution of the accuracy values while the second parameter (i.e. dz2) might denote a skewed distribution of the estimated values. It should be noted however that the estimated values of all elevation accuracies were within the acceptable limits of international standards.

\section{Discussion and Conclusion}

As widely known in the related literature production of digital orthophotos deals with many steps and each step entails some errors which can propagate to digital orthophotos. The motive of this paper is to investigate the accuracy of digital orthophotos using these steps. Some main factors that affect digital orthophoto accuracy is briefly discussed throughout the study. Because accuracy assessment of digital orthophotos is a complicated issue, the method of combining theory with practice might be a suitable approach. For this goal it is aimed to investigate the accuracy of digital orthophotos produced in a project for large scale (i.e. 1/1000) digital photogrammetric map and orthophoto production in Kocaeli city. A geodetic field surveys were employed to check and produce a reliable point network in the project area. GPS measurements provided an accurate positional network for the ground points in the study area and levelling measurements were made to check existing elevation points. The estimated accuracies in the project provided that the produced digital orthophotos could be used for producing large scale standard national maps even in an unstable ground district (i.e. due to the fault lines) like Izmit. The geomorphological features of the İzmit Bay and its ground conditions have endangered a strong effect increasing the damage of the Izmit earthquake. In progress of time, fault motions have induced positional deformation at the GCPs. When determining the accuracy of an orthophoto, deformations at these points directly affect orthophoto accuracy. Note that all the estimated accuracy results obtained in the study were found to be within acceptable standard limits. Since the geodetic surveys were made in parallel to the photogrammetric triangulation in the project area, accurate digital orthophotos could be produced as can be seen from the accuracy assessment findings. Then the existing ground control networks should be monitored and updated precisely for determined periods as fault motions induce positional deformation at the ground control points.

\section{Acknowledgements}

We would like to thank to Kocaeli Metropolitan Municipality and the private sector firm titled "Kutlubey Harita İnş.Müh.San.Tic. A.Ş" for inviting us to participate to this large scale digital orthophoto production project (December 2010).

\section{References}

Amhar, F., and Ecker, R. (1995). Accurate Mapping of Buildings in Digital Orthophotos, Proceeding of 17th 
International Conference of Cartography, Barcelona, pp. $605-609$

Arslan O., (2010). 1/1000 Large Scale Digital Photogrammetric Map and Color Orthophoto Production in Kocaeli (Kocaeli İli 1/1000 Ölçekli Sayısal Fotogrametrik Halihazır Harita ve Renkli Ortofoto Harita Üretimi).

ASPRS Positional Accuracy Standards for Digital Geospatial Data. (2015), Photogrammetric Engineering and Remote Sensing, 81(3), 1-26

Bahadur, B., Nohutçu, M. (2020). MULTI-GNSS PPP: An Alternative Positioning Technique for Establishing Ground Control Points, International Journal of Environment and Geoinformatics, 7(1): 88-92, doi: 10.30897/ijegeo.710304

Bayram, Bülent, Inese Janpaule, Mustafa Oğurlu, Salih Bozkurt, Hatice Çatal Reis, Dursun Zafer Şeker (2015). Shoreline Extraction and Change Detection Using 1:5000 Scale Orthophoto Maps: A Case Study of Latvia-Riga. International Journal of Environment and Geoinformatics 2(3), 16.doi:10.30897/ijegeo.303552.

Çelik, İ., Gazioğlu, C. (2020). Coastline Difference Measurement (CDM) Method, International Journal of Environment and Geoinformatics, 7(1): 1-5. 10.30897/ijegeo.706792.

Chiabrando, F., Nex, F., Piatti, D., and Rinaudo, F. (2011). UAV and RPV Systems for Photogrammetric Surveys in Archaelogical Areas: Two Tests in The Piedmont Region (Italy). Journal of Archaeological Science, 38(3), 697-710. doi: 10.1016/j.jas.2010.10.022

Dalamagkidis, K., Valavanis, K. P., and Piegl, L. A. (2008). Current Status and Future Perspectives for Unmanned Aircraft System Operations in the US. Journal of Intelligent and Robotic Systems, 52(2), 313-329. doi: 10.1007/s10846-008-9213-x

Ettarid, M., Ait M'hand, A., and Aloui, R. (2005). Digital True Orthophotos Generation, From Pharaohs to Geoinformatics FIG Working Week 2005 and GSDI-8 Cairo, Egypt

Fradkin, M., and Ethrog, U. (1997). Feature matching for automatic generation of distortionless digital orthophoto. Integrating Photogrammetric Techniques with Scene Analysis and Machine Vision III (Eds. D. M. McKeown, Jr., J. C. McGlone and O. Jamet). SPIE 3072: 153-164.

Grenzdörffer, G.; Engel, A.; Teichert, B. (2008) The Photogrammetric Potential of Low-Cost UAVs In Forestry and Agriculture. The International Archives of the Photogrammetry, Remote Sensing and Spatial Information Sciences, 31, 1207-1214

Ioannou, M. T., and Georgopoulos, A. (2013). Evaluating Large Scale Orthophotos Derived from High Resolution Satellite Imagery. First International Conference on Remote Sensing and Geoinformation of the Environment (RSCy2013). doi: $10.1117 / 12.2028336$

Karasaka, L., Karabörk, H., Güntel, A., Esirtgen, F. (2017). Geometric Analysis of Digital Aerial Images, International Journal of Environment and
Geoinformatics, 10.30897/ijegeo.706792.

Krupnik A., (2003). Accuracy Prediction for OrthoImage Generation, The Photogrammetric Record, 18(101), 41-58. doi: 10.1111/0031-868x.t01-1-00001

Kulur S, Yildiz F, Selcuk O, and Yildiz M.A., (2016). The Effect of Pixel Size on the Accuracy of Orthophoto Production, ISPRS Annals of the Photogrammetry, Remote Sensing and Spatial Information Sciences, III-4, 53-57. doi: 10.5194/isprs-annals-iii-4-53-2016

Mesas-Carrascosa, F., Rumbao, I., Berrocal, J., and García-Ferrer, A. (2014). Positional Quality Assessment of Orthophotos Obtained from Sensors Onboard Multi-Rotor UAV Platforms. Sensors, 14(12), 22394-22407. doi: 10.3390/s141222394

Rau, Jiann-Yeou and Chen, N.Y and Chen, L.C. (2002). True Orthophoto Generation of Built-up Areas Using Multi-View Images. Photogrammetric Engineering and Remote Sensing, 68(6). 581-588.

Sai, SS., Tjahjadi, ME., Rokhmana, CA. (2019). Geometric Accuracy Assessments of Orthophoto Production from UAV Aerial Images, GEODETA 2019 The 1st International Conference on Geodesy, Geomatics, and Land Administration 2019, 333-344.

Simard P. G. (1997). Accuracy of Digital Orthophotos (Master Thesis), The University of New Brunswick.

Smith, M. J., Smith, D. G., Tragheim, G., and Holt, M. (1997). DEMs and Ortho-Images from Aerial Photographs. The Photogrammetric Record, 15(90), 945-950. doi: 10.1111/0031-868x.00104

Udin, W. S., and Ahmad, A. (2014). Assessment of Photogrammetric Mapping Accuracy Based on Variation Flying Altitude Using Unmanned Aerial Vehicle. IOP Conference Series: Earth and Environmental Science, 18, 012027. doi: 10.1088/1755-1315/18/1/012027

Wierzbicki, D., Kedzierski, M., and Fryskowska, A. (2015). Assesment of the Influence of UAV Image Quality on the Orthophoto Production. ISPRSInternational Archives of the Photogrammetry, Remote Sensing and Spatial Information Sciences, XL-1/W4, 1-8. doi: 10.5194/isprsarchives-xl-1-w4-12015. 